
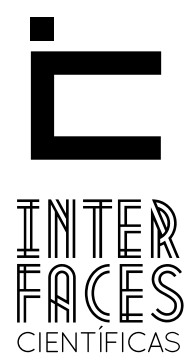

DIREITO

\title{
O PAPEL DA EDUCAÇ̃̃O AMBIENTAL NO ESTUDO DAS FONTES RENOVÁVEIS DE ENERGIA NAS ESCOLAS BRASILEIRAS
}

\author{
Fernanda Campos Maia Wrobel ${ }^{1}$
}

\section{RESUMO}

Este artigo analisou a importância da implementação do estudo dos recursos naturais renováveis, como fonte alternativa de energia, nas escolas brasileiras, por meio da Educação Ambiental. Discutiu-se como a Educação Ambiental pode alterar padrões de comportamentos, e ser vista como degrau para a valorização do meio ambiente, tendo em vista a conexão entre uso da energia e danos ao meio ambiente. Analisou os conceitos e vantagens da utilização dos recursos naturais renováveis e como a educação ambiental surge como agente formador da cidadania ecológica, na medida em que, identifica a importância e a necessidade da utilização desses recursos naturais renováveis como uma nova forma de se pensar o planeta. Analisou o tema educação ambiental sob o ponto de vista do discurso ecológico oficial e o alternativo, bem como as dificuldades de se efetivar o discurso ecológico alternativo dentro do ambiente escolar. Demonstrou como a educação ambiental deve transcender os limites da escola, indo além do currículo, do método e dos anseios do mercado, e atingir todo o espaço social. Considerou a Educação Ambiental como um instrumento formal e informal de educação na busca de se atingir a sustentabilidade. Analisou, também, as formas de se implementar o uso das fontes energéticas renováveis. A metodologia utilizada foi a pesquisa bibliográfica de cunho qualitativo, alicerçada em doutrina, artigos científicos, pesquisas relacionada ao tema. 0 marco teórico é a Lei de Política Nacional de Educação Ambiental, sob o no 9.795/99, devendo estar presente em todos os níveis e modalidades do processo educativo nacional, trazendo a permanente avaliação crítica, a adequação dos conteúdos à realidade local e o envolvimento dos atores em ações concretas para transformação de uma realidade.

\section{PALAVRAS-CHAVE}

Energias Renováveis. Educação Ambiental. Meio Ambiente. 


\section{ABSTRACT}

This article analyzed the importance of implementing the study of renewable natural resources as an alternative energy source, in Brazilian schools, through the Environmental Education. Discussed how environmental education can change behavior patterns, and be seen as a step for the development of the environment in view of the connection between energy use and environmental damage. Analyzed the concepts and advantages of the use of renewable natural resources and how environmental education emerges as forming agent of ecological citizenship, in that it identifies the importance and the necessity of the use of these renewable natural resources as a new way of thinking about the planet. Analyzed the environmental education theme from the point of view of the official ecological discourse and the alternative as well as the difficulties of effecting the alternative ecological discourse within the school environment. Demonstrated how environmental education should go beyond the school grounds, going

\section{RESUMEN}

En este trabajo se analiza la importancia de aplicar el estudio de los recursos naturales renovables como fuente de energía alternativa, en las escuelas brasileñas, a través de la Educación Ambiental. Discutió cómo la educación ambiental puede cambiar los patrones de comportamiento, y se ve como un paso para el desarrollo del medio ambiente teniendo en cuenta la relación entre el uso de la energía y el daño ambiental. Analizando los conceptos y ventajas de la utilización de los recursos naturales renovables y cómo la educación ambiental surge como agente de formación de la ciudadanía ecológica, ya que identifica la importancia y la necesidad de la utilización de estos recursos naturales beyond the curriculum, method and market concerns, and reach all the social space. Considered the environmental education as an instrument of formal and informal education in the pursuit of achieving sustainability. Analyzed also the ways to implement the use of renewable energy sources. The methodology used in this bibliographic research with qualitative approach, grounded in doctrine, scientific articles, research related to the topic. The theoretical framework is the National Environmental Education Policy Act, under No. 9.795 / 99, which must be present at all levels and modalities of the national education process, bringing the ongoing assessment review, the adequacy of the contents of the local reality and the implications the actors in concrete actions for processing a reality.

\section{KEYWORDS}

Renewable Energy. Environmental Education. Environment.

renovables como una nueva forma de pensar sobre el planeta. Analizado el tema de la educación ambiental desde el punto de vista del discurso ecológico oficial y la alternativa, así como las dificultades de efectuar el discurso ecológico alternativo en el entorno escolar. Demostrar cómo la educación ambiental debe ir más allá de los terrenos de la escuela, yendo más allá de los planes de estudio, de método y de mercado, y así, llegar a todo el espacio social. Considerada como la educación ambiental como un instrumento de educación formal e informal en la búsqueda de lograr la sostenibilidad. Se analizó también las formas de implementar el uso de fuentes de energía renovables. La metodología utilizada en esta investigación bibliográfica con enfoque cualitativo, fundamentado en la doctrina, 
artículos científicos, la investigación relacionada con el tema. El marco teórico es la Ley de Política Nacional de Educación Ambiental, bajo el N 9.795 / 99 , que debe estar presente en todos los niveles y modalidades del proceso de la educación nacional, con lo que el examen de la evaluación continua, la adecuación de los contenidos de la realidad local y

\section{INTRODUCÇÃO}

Para se entender a importância da aplicabilidade do estudo das energias renováveis dentro do ambiente educacional brasileiro, necessário se faz discorrer algumas considerações iniciais sobre a abrangência do conceito de recursos naturais renováveis, suas vantagens e como a educação ambiental surge como agente formador da cidadania ecológica, na medida em que identifica a importância e a necessidade da utilização desses recursos naturais renováveis como uma nova forma de se pensar o planeta.

Rios (2006) aponta que o aumento da demanda de energia é um processo natural e irreversível e está baseado no crescimento populacional, na busca da meIhoria de qualidade de vida das populações, e na democratização da energia. Por isso, justifica Goldemberg e Villanueva (2001) que a conexão energia-meio ambiente tem sido objeto de muitos estudos e, algumas vezes, é possível estabelecer uma relação de causa e efeito entre o uso da energia e os danos ao meio ambiente.

Tanto é assim, que diminuição dos problemas ambientais, tais como, esgotamento dos recursos naturais, chuva ácida, efeito estufa e mudanças climáticas globais, passa pelo uso, em larga escala, de fontes renováveis de energia.

Assevera Rios que para implementação do estudo do uso dessas fontes renováveis de energia, no ambiente es- las implicaciones los actores en acciones concretas para la transformación de una realidad .

\section{PALABRAS CLAVE}

Energía Renovable. Educación Ambiental. Medio Ambiente. colar, são necessárias algumas atividades, entre elas, a saber: a adoção de um sistema de ensino completamente direcionado no uso adequado das fontes renováveis de energia; pesquisa de excelência em fontes renováveis de energia e a disseminação do conhecimento tecnológico dessas fontes renováveis de energia (RIOS, 2006).

É de fácil constatação que o planeta pede socorro pelo uso inadequado e predatório dos recursos naturais. Entretanto, como uma reação em sentido oposto, torna-se fundamental educar os cidadãos, não apenas para a aquisição de conhecimento, mas para o seu uso ético e responsável, conforme lecionam Hartmann e Zimmermann (2007).

Sabe-se que a efetividade de minimizar os impactos ambientais, na sociedade de hoje, perpassa por ações de Educação Ambiental.

Importante ressaltar que a Educação Ambiental no Brasil remete-se a dois pontos de vista diametralmente opostos sobre o assunto. Existem aqueles que entendem ser esse um tema menor dentro da pauta ambiental e aqueles que acreditam ser a Educação Ambiental o eixo central das questões relacionadas à proteção ao meio ambiente.

Para aqueles que não veem tanta relevância no tema, seria a Educação Ambiental apenas mais uma 
entre tantas temáticas. Assim, questões como a sustentabilidade, legislações, licenciamentos e outros temas, por exemplo, seriam questões mais importantes a serem tratados nesta seara.

Para os que garantem importância fundamental à Educação Ambiental, a justificativa estaria no fato dela estar presente, de maneira indelével, na maioria dos temas referentes ao meio ambiente, sendo um recorte transversal a todos os campos da matéria. Essa possibilidade garante à Educação Ambiental um caráter universal e, por isso, importante para o desafio de se criar estratégias de preservação ao meio ambiente. Prova disso, é a referência direta fundamentada no artigo 225 da Constituição Federal de 1998, mais precisamente no seu parágrafo primeiro, inciso $\mathrm{VI}^{2}$.

Entende-se, que a temática Educação Ambiental é fundamental e deve estar inserida nas pautas mais importantes a serem debatidas em nosso País. 0 equívoco cometido por aqueles que não acreditam na importância desse assunto, pode estar em um problema de conceituação do termo Educação Ambiental. Esta, normalmente entendida, de maneira rasa e descontextualizada, o que leva a problemática para um campo de julgamento de valores, imutáveis e maniqueístas, tutelados por uma prática pedagógica mecânica e engessada, o que não contribui para a efetiva proteção do meio ambiente.

\section{IMPORTÂNCIA DOS RECURSOS NATURAIS RE- NOVÁVEIS NO BRASIL}

Os recursos naturais podem ser entendidos como bens que são extraídos da natureza de forma direta ou indireta, e são transformados para a utilização na vida do ser humano 3 . Podem ser divididos em recursos naturais renováveis e não renováveis.

2. Nota: Art. 225. Todos têm direito ao meio ambiente ecologicamente equilibrado, bem de uso comum do povo e essencial à sadia qualidade de vida, impondo-se ao Poder Público e à coletividade o dever de defendê-lo e preservá-lo para as presentes e futuras gerações.

$\S 1^{\circ}$ - Para assegurar a efetividade desse direito, incumbe ao Poder Público:

$\mathrm{VI}$ - promover a educação ambiental em todos os níveis de ensino e a conscientização pública para a preservação do meio ambiente.

3. Disponivel em: http://www.significados.com.br/recursos-naturais/
Segundo Roger e Merlin (2010), os recursos naturais renováveis podem ser entendidos como aqueles que se perpetuam naturalmente, como por exemplo, o sol, as plantas, solo e a vida animal; já os recursos naturais não renováveis são aqueles que não se perpetuam e são limitados em sua quantidade no planeta, por exemplo, os minerais e os combustíveis fósseis.

Até a década de 1970 não se discutia sobre alternativas energéticas no mundo. Foi com a crise mundial do petróleo que se percebeu que as reservas de combustíveis fósseis eram limitadas e que algumas fontes energéticas poluíam e poluem seriamente o planeta.

Do ponto de vista de Walter e Nogueira (2008), a crise do petróleo proporcionou o desenvolvimento e revalorização de novas tecnologias voltadas à produção de energia elétrica de fontes renováveis, particularmente no formato de cogeração:

\begin{abstract}
Entretanto, a partir do final da segunda metade dos anos 1970, o setor elétrico entrou em uma nova fase em vários países. As reformas institucionais do setor tiveram início em função da elevação dos custos de geração de energia elétrica segundo tecnologias convencionais, tanto por razões tecnológicas quanto ambientais e também devido ao processo recessivo dos países industrializados em associação aos choques dos preços do petróleo. Essas reformas, eminentemente de caráter descentralizador, resultaram na revalorização da co-geração, na produção elétrica em pequena escala, no uso mais intensivo de fontes energéticas renováveis e na produção independente. (WALTER e NOGUEIRA, 2008, p. 573).
\end{abstract}

Então, a partir dessa época, as fontes de energia não renováveis deveriam ser pensadas como produtos poluentes e agravadores da situação ecológica da terra e, por isso, alternativas ao seu uso eram muito bem-vindas.

No final do século $X X$, em razão da crescente demanda por energia, impulsionada pelo desenvolvimento demográfico e econômico progressivo 
do país, iniciou-se, no Brasil, um período de reorganização estrutural e operacional do sistema energético nacional.

O desenvolvimento sustentável tornou-se uma realidade indiscutível nos primeiros anos do século atual e a busca pelo equilíbrio entre os progressos econômico, ambiental e social é pauta constante nos encontros nacionais e internacionais.

O Brasil desponta com destaque no âmbito mundial no que concerne à sustentabilidade, já que sua matriz energética essencialmente hídrica, recurso natural renovável, é menos poluente e agressiva ao meio ambiente se comparada com outras fontes de energia, principalmente com os combustíveis fósseis. Acontece que a excessiva dependência desse modelo torna o país refém dos diversos problemas estruturais existentes e sujeito as intempéries ambientais, como as irregularidades do regime fluvial vivenciadas nos anos passados.

Atualmente, muita importância é dada a energia renovável, obtida de fontes naturais capazes de se regenerar e se renovar. Por essa razão, o incentivo em pesquisas por fontes alternativas e renováveis são indispensáveis para fomentar a diversificação do parque energético brasileiro.

Energia eólica, solar, biomassa, hidrelétrica, geotérmica são alguns exemplos de fonte de energia renovável

\section{EDUCAÇÃO AMBIENTAL COMO INSTRUMENTO DE ENFRENTAMENTO DOS PROBLEMAS AMBIENTAIS}

Ensinam Talomani e Sampaio (2003) que a educação ambiental passa a ser uma ação estratégica importante para o enfrentamento dos problemas ambientais que se agravam ao longo do tempo.

\subsection{CONCEITO DE EDUCACX̃O AMBIENTAL}

A educação ambiental ainda é um tema recente e, como toda temática em fase de afirmação, recebeu várias definições ao longo de sua escala evolucionária. De acordo com Reigota (1995) o conceito de Educação Ambiental está vinculado ao ambiente e a forma como este é percebido. Ela não se restringe ao ensino de ecologia e ao ensino de ciências, e também não se caracteriza como uma ciência capaz de modificar comportamentos ambientais predatórios.

Segundo Talomoni e Sampaio (2003) a Educação Ambiental passou a ser entendida como um processo de construção da relação humana com o ambiente, bem como uma atividade intencional da prática social, que imprime ao desenvolvimento individual um caráter social em sua relação com a natureza e com os outros seres humanos, com o objetivo de potencializar essa atividade humana, tornando-a mais plena de prática social e de ética ambiental.

Ensina Chalita (2002) que a Educação Ambiental pode ser uma poderosa ferramenta de intervenção no mundo para construção de novos pensamentos e consequente mudança de hábitos, além de ser importante instrumento de construção de conhecimento.

Na Conferência de Tbilisi, em 1977, a Educação Ambiental foi definida como sendo uma dimensão dada ao conteúdo e à prática da educação, orientada para a resolução dos problemas concretos do meio ambiente, por meio de enfoques interdisciplinares e de uma participação ativa e responsável de cada indivíduo e da coletividade.

\subsection{A EDUCAÇÃO AMBIENTAL NO CONTEXTO INTERNACIONAL}

A origem da Educação Ambiental é relativamente recente e está ligada a Organismos Internacionais. Segundo Barbieri e Silva (2009), desde a criação da UNESCO em 1946, pela ONU, o tema Educação Ambiental está em foco, sempre mobilizando a sociedade civil e o poder público dos países. 
Loureiro (2012) aponta que o termo Educação Ambiental foi usado pela primeira vez em um encontro na Universidade de Keele, Reino Unido em 1965. Mas, foi na Conferência das Nações Unidas sobre o Ambiente Humano, na cidade de Estocolmo, em 1972, que a articulação entre educação e meio ambiente foi evidenciada e colocada em pauta pela ONU, obtendo, dessa forma, projeção internacional. Mais uma vez, o debate e as contingências internacionais são a força motriz dessa importante discussão.

Ainda dentro da evolução e da aplicabilidade do tema, Loureiro (2012), aponta que a Organização para a Educação, Ciência e Cultura (UNESCO) e o Programa das Nações Unidas para o Meio Ambiente (PNUMA) foram os responsáveis por elaborar o Programa Internacional de Educação Ambiental (PIEA). Esse último, definido como o organismo internacional encarregado de organizar os encontros no âmbito regional e nacional, bem como articulá-lo em boletins informativo em várias línguas.

Barbieri e Silva (2009, p. 54), destacam que a Conferência de Estocolmo de 1972, trouxe aspectos específicos referentes à Educação Ambiental e afirmam:

\begin{abstract}
Durante a Conferência das Nações Unidas para o Meio Ambiente Humano (CNUMAH), realizada em Estocolmo, em 1972, foram criados alguns instrumentos para tratar de problemas sociais e ambientais planetários, como a Declaração sobre o Ambiente Humano, com 26 princípios voltados para orientar a construção de ambiente que harmonize os aspectos humanos e naturais, considerados essenciais para o bem-estar dos humanos e para que possam gozar de todos os direitos fundamentais.
\end{abstract}

De acordo com um desses princípios, é indispensável um trabalho de educação em questões ambientais, dirigido para jovens e adultos.

$\mathrm{Na}$ medida em que as discussões sobre o tema foram sendo amadurecidas, novos eventos sobre o assunto foram surgindo. Para Loureiro (2012), foi por meio das articulações promovidas pela UNESCO/
PNUMA/PIEA que a Educação Ambiental foi ganhando um caráter específico, culminando na realização, em 1975, do I Seminário Internacional de Educação Ambiental, em Belgrado. São méritos desse evento:

O grande mérito deste seminário foi, apesar de resvalar em um certo ecologismo liberal, foi reforçar a necessidade de uma nova ética global e ecológica. Vinculada aos processo de erradicação de problemas como fome, miséria, analfabetismo, poluição, degradação dos bens naturais e exploração humana por meio de um novo modelo de desenvolvimento e do entendimento de que tais problemas estão estruturalmente relacionados. Para isso, enfatizou-se a Educação Ambiental como o processo educativo amplo, formal ou não, abarcando as dimensões políticas, culturais e sociais, capaz de gerar novos valores, atitudes e habilidade compatíveis coma sustentabilidade de vida no planeta. (LOUREIRO, 2012, p. 78).

De lá pra cá diversos eventos relacionado à Educação Ambiental ocorreram, buscando formas de promover a articulação entre meio ambiente e educação. Loureiro (2012, p. 78) destaca alguns destes eventos:

Taller Subregional de Educacición Ambiental para Educación Secundaria, realizado em Chosica, Peru, em 1976, que possui um das mais complexas abordagens em Educação Ambiental. Foi um dos primeiros eventos regionais... no qual afirmou a necessidade metodológica de Educação Ambiental ser participativa, permanente, interdiciplinas, construída a partir da realidade cotidiana, com implicações sobre o formato curricular no ensino formal (UNESCO, 1976).

Outro evento citado por Loureiro (2012) foi a Conferência Intergovernamental, realizada em Tbilisi, em 14 a 26 de outubro de 1977, em que se buscou identificar a Educação Ambiental como o caminho para se articular os aspectos ambientais junto com os aspectos sociais. Segundo Loureiro (2012), nessa conferência a problematização da realidade e a busca pela solução da crise da sociedade deram a tônica das discussões, e as recomendações do evento foram a implantação de políticas públicas para consolidação e universalização da Educação Ambiental. 
Ainda segundo Loureiro (2012, p. 81-82), pode-se destacar outros eventos de grande relevância para a consolidação da Educação Ambiental, a saber:

O Seminário Educação Ambiental para América Lati-
na, realizado na Costa Rica, em 1979, e o Seminário
Latino-Americano de Educação Ambiental, ocorrido
na Argentina, em 19888, que reforçaram a necessida-
de de preservação do patrimônio histórico - cultural e
a função estratégica da mulher na promoção do desen-
volvimento local e das culturas ecológicas. O Congres-
so Internacional de Educação e Formação Ambientais,
sucedido em Moscou, no ano de 1987, que ao avaliar
os avanços obtidos e ratificar as diretrizes de Tbilisi,
enfatizou o estímulo à organização de redes de infor-
mação e comunicação entre profissionais. A jornada
Interamericana de Educação Ambiental, realizada no
Rio de Janeiro, em 1992, paralela à Conferencia Ofi-
cial, na Rio 92, na qual foi produzido o já destacado
Tratado de Educação Ambiental para a Sociedades
Sustentáveis e Responsabilidade Global.

O Tratado de Educação Ambiental para Sociedades Sustentáveis e Responsabilidade Global, segundo Loureiro (2012, p. 82) "expressa o que os educadores de países de todos os continentes pensam em relação à Educação Ambiental e estabelece um conjunto de compromissos coletivos para a sociedade civil planetária”.

Esse autor encerra seu resgate histórico sobre a Educação Ambiental no mundo, ao apresentar a Conferência Meio Ambiente e Sociedade: Educação e Consciência pública para a Sustentabilidade, que ocorreu em Thessaloniki em 1997. Essa conferência buscou dar prioridade a "formação de professores, a produção de materiais didáticos e a realização de encontros de menor porte para a troca de experiências entre educadores" (LOUREIRO, 2012, p. 82).

Ele, ainda, alerta para o fato de que as discussões em torno da cidadania e da ética estiveram presentes em todas as conferências internacionais elencadas, além dos questionamentos e cobranças à emergência de uma nova postura da sociedade, em virtude das necessidades ambientais impostas em nosso tempo. Ainda assim, questiona o excessivo caráter genérico desses documentos, que impediram que as mudanças propostas por eles fossem concretizadas, já que foram cooptadas e aplicadas segundo os interesses individuais.

\subsection{SURGIMENTO DA EDUCAÇ̃̃O AMBIENTAL NO BRASIL}

Afirma Carvalho (2001) que na década de 1970, não existia qualquer política educacional que mencionasse a Educação Ambiental em seu conteúdo no Brasil.

De acordo com Leite (2001), alguns acontecimentos influenciaram o surgimento da educação ambiental no Brasil, são eles:

0 primeiro deles foi a criação da Secretaria Especial do Meio Ambiente, SEMA, no âmbito do Ministério do Interior, que, entre outras atividades, contemplou a Educação Ambiental, em 1973.

Em 1977, a SEMA constitui um grupo de trabalho para a elaboração de documentos sobre a Educação Ambiental, definindo o seu papel no contexto brasileiro.

Aconteceram seminários, encontros e debates preparatórios à Conferência de Tbilisi.

A Secretaria de Educação do Rio Grande do Sul desenvolveu o Projeto Natureza (1978 -1985). Houve a criação de cursos voltados às questões ambientais em várias universidades brasileiras, em 1978.

O Conselho Nacional do Meio Ambiente (CONAMA) apresentou uma resolução, estabelecendo diretrizes para a Educação Ambiental, em 1984.

Em 1987, o Ministério da Educação (MEC) aprovou o Parecer $n^{\circ}$ 226/87, do conselheiro Arnaldo Niskier - inclusão da Educação Ambiental nos currículos escolares de $1^{\circ}$ e $2^{\circ}$ graus.

A Constituição Brasileira de 1988, art. 225 no capítulo “VI - Do Meio Ambiente, inciso VI - destacou 
a necessidade de promover a educação ambiental em todos os níveis de ensino e a conscientização pública para a preservação do meio ambiente" (BRASIL, 1988). Para cumprimento dos preceitos constitucionais, leis federais, decretos, constituições estaduais e leis municipais determinaram a obrigatoriedade da educação ambiental.

Já em 1989, houve a criação do Instituto Brasileiro do Meio Ambiente e dos Recursos Naturais Renováveis (IBAMA), pela fusão da SEMA, SUDEPE, SUDHEVEA e IBDF, onde funcionava a Divisão de Educação Ambiental. Criou-se, também, o Fundo Nacional do Meio Ambiente (FNMA) no Ministério do Meio Ambiente (MMA), apoiando projetos que incluem a Educação Ambiental.

Em 1991, o MEC, por meio da Portaria no 678 (14/05/91) instituiu que todos os currículos nos diversos níveis de ensino deveriam contemplar conteúdos de Educação Ambiental.

Em 1992, houve a criação dos Núcleos Estaduais de Educação Ambiental do IBAMA (NEAs). Houve participação das ONGs do Brasil no Fórum de ONGs e na redação do Tratado de Educação Ambiental para Sociedades Sustentáveis.

Já em 1993, criou-se os Centros de Educação Ambiental do MEC, com a finalidade de criar e difundir metodologias em educação ambiental.

Em 1994, houve a aprovação do Programa Nacional de Educação Ambiental (PRONEA), com a participação do MMA-IBAMA-MEC-MCT-MINC.

Em 1996, criou-se a Câmara Técnica de Educação Ambiental, CONAMA. Criados também novos Parâmetros Curriculares do MEC que incluem a educação ambiental como tema transversal do currículo (Lei 9.394/96).

Houve a criação da Comissão de Educação Ambiental do MMA, em 1997 (LEITE, 2001, p. 265-269).
Só em 1999 que se instituiu a obrigatoriedade da Educação Ambiental em todos os níveis de ensino formal no Brasil, a partir da promulgação da Lei de Política Nacional de Educação Ambiental, sob o $n^{\circ} 9.795 / 99$. Essa lei foi fruto de um longo processo de interlocução entre ambientalistas, educadores e poder público. A referida lei estabelece em seu art. 10, parágrafo primeiro que "A educação ambiental não deve ser implantada como disciplina específica no currículo de ensino" (BRASIL, 1999). Isso significa que a Educação Ambiental deve ser abordada e entendida a partir de uma visão inter e multidisciplinar, buscando o entendimento e soluções para os graves problemas ambientais que temos hoje.

Diante dessa trajetória, percebe-se que a Educação Ambiental nasceu da gestão ambiental e, só mais tarde, passa a ser incorporada pela política educacional.

\section{A EDUCACÃO AMBIENTAL NO ENFRENTAMENTO DOS PROBLEMAS AMBIENTAIS}

Os problemas ambientais são problemas de conhecimento, e segundo Leff (2001) para a efetivação de qualquer política ambiental deve-se levar em conta a educação, traduzida aqui como uma política de conhecimento.

A partir dessa nova consciência, a escola é chamada para contribuir na solução ou amenização da crise ambiental vivida atualmente.

De acordo com o MEC, o poder público deve apoiar a comunidade escolar, em todos os níveis e modalidades de ensino, a se tornarem educadores ambientais com uma leitura crítica da realidade contemporânea.

Para propiciar essa educação ambiental nas escolas, o MEC criou o programa Vamos Cuidar do Brasil com as Escolas. Esse programa contém ações e prá- 
ticas integradas, contínuas e transversais a todas as disciplinas ${ }^{4}$.

Segundo Carvalho (2006. p. 17), a educação ambiental tem o grande desafio de garantir a "construção de uma sociedade sustentável, em que se promovam valores éticos de cooperação, solidariedade, generosidade, tolerância e dignidade na relação entre o planeta e seus recursos".

Afirma ainda que a "educação ambiental é conteúdo e aprendizado, é motivo e motivação, é parâmetro e norma" (CARVALHO, 2006. p. 17). Daí, entende-se que a Educação Ambiental vai além de conteúdos pedagógicos, deve interagir com o homem e com a sociedade.

É fundamental, a partir do que foi dito, que a escola mude suas regras para se implementar a Educação Ambiental de uma forma mais prática e coletiva, ou seja, o conhecimento torna-se aprimorado quando é construído coletivamente, na medida em que transmitir seu conhecimento é, também, aprender com o conhecimento do outro.

A Educação Ambiental deve surgir como agente formador da cidadania ecológica, com senso crítico e fazendo parte de uma educação política.

\subsection{EDUCAÇ̃̃O AMBIENTAL E CIDADANIA}

Segundo os Parâmetros Curriculares Nacionais $(1997)^{5}$ a principal função da educação é contribuir para a formação de cidadãos conscientes, aptos para decidirem e atuarem na realidade socioambiental de um modo comprometido com a vida, com o bem estar de cada um e da sociedade, local e global. Porém, o grande desafio para a escola é tornar tudo isso possível a partir de uma proposta de aprendizagem basea-

4. Pode ser encontrado no Ministério do Meio Ambiente. Departamento de Educação Ambiental. Vamos cuidar do Brasil: conceitos e práticas em educação ambiental na escola [Coordenação: Soraia Silva de Mello, Rachel Trajber]. - Brasília: Ministério da Educação, Coordenação Geral de Educação Ambiental: Ministério do Meio Ambiente, Departamento de Educação Ambiental: UNESCO, 2007.

5. PARÂMETROS CURRICULARES NACIONAIS. Meio ambiente/saúde / Secretaria de Educação Fundamental. Brasília: 1997. da nas mudanças de atitudes e formação de valores, com enfoque e para a realidade vivida.

O convívio escolar é decisivo na aprendizagem de valores sociais, inclusive para impulsionar o uso de fontes de energias renováveis, na medida em que se torna questão imperativa para o meio ambiente ecologicamente equilibrado.

A realização de atividades que visem o bem-estar da comunidade escolar com a participação dos alunos, a mudança de mentalidade para se pensar o espaço, bem como a participação da comunidade escolar na formulação, definição e controle de políticas públicas a elas relacionadas são fatores fundamentais na construção da identidade desses alunos como cidadãos.

\subsection{EDUCAÇ̃̃O AMBIENTAL E O SENSO CRÍTICO}

De acordo com os Parâmetros Curriculares Nacionais (1997) a proposta de inserir a Educação Ambiental no cotidiano das pessoas, tem como objetivo embasar as comunidades exploradas e manipuladas para que estas possam opinar, criticar e se organizar para reivindicarem seus direitos. Dessa maneira, desenvolver o senso crítico é a maneira mais eficiente de se educar ambientalmente as pessoas.

Os problemas ambientais são fruto de um contínuo processo de degradação, de falta de compromisso com o meio ambiente. Alguns desses problemas são eternos e não podem mais ser mitigados, mas existem outros que devem ser estudados e instrumentalizados para que tornem a vida no planeta mais sadia para as presentes e futuras gerações. Um desses problemas atuais relevantes que a sociedade enfrenta é o a maneira que se usa as fontes de energia, advindas dos recursos naturais. As preocupações com aquecimento global, com efeito estufa, dentre outros, estão intimamente relacionadas com a forma de energia que se usa. A procura por fontes alternativas de energia renováveis está na ordem do dia, é uma questão de qualidade de vida para a humanidade. 


\subsection{EDUCAÇ̃̃O AMBIENTAL COMO EDUCAÇ̃̃O POLÍTICA}

Segundo Reigota (1994) a Educação Ambiental deve orientar-se, também, para a comunidade, incentivando a participação de todos os envolvidos na resolução de problemas, inclusive, ambientais. Assim, mesmo com a visão de que a Educação Ambiental não resolverá os complexos problemas ambientais planetários, tem-se a consciência de que pode influir decisivamente para isso, quando forma cidadãos conscientes dos seus direitos e deveres. Assevera o autor que o desafio que se coloca é de formular uma Educação Ambiental que seja crítica e inovadora, em dois níveis: nível formal e não formal.

Dessa maneira, a Educação Ambiental deve ser, acima de tudo, um ato político voltado para a transformação social. O seu enfoque deve buscar uma perspectiva de ação holística que relaciona o homem, a natureza, a sociedade e o poder público.

Diante disso, importante observar que a escola deve ser um espaço, com concepções pedagógicas para o desenvolvimento de uma ética ambiental, com implementação de atividades de conscientização, experimentos, capacitação para toda a comunidade escolar, ou seja, a Educação Ambiental deve ser apresentada como disciplina da prática dentro e fora da escola, não apenas apresentada como conceito meramente teórico.

\section{A EDUCAÇÃO AMBIENTAL NAS ESCOLAS BRASILEIRAS}

Inicialmente, deve-se observar, segundo Carvalho (1991), a existência de dois discursos sobre a questão ambiental. Primeiro, um discurso ecológico oficial, representante da ideologia hegemônica e, segundo, um discurso ecológico alternativo, representante da ideologia contra hegemônica.

Entende Layrargues (2002), que o ideário do discurso ecológico alternativo opõe-se ao discurso eco- lógico oficial. Enquanto o oficial deseja manter o status quo, o alternativo deseja transformá-lo.

A educação ambiental baseada no discurso alternativo é dita como progressista, e deve ser concebida como meio de transformação social, promovendo reflexão dos valores fundamentais da comunidade escolar, das instituições e da própria sociedade.

Além disso, no que concerne ao ambiente escolar, ensina Leite (2001, p. 124) que o "conteúdo da educação ambiental está enquadrado no grupo denominado temas transversais". Isso quer dizer que o tema Educação Ambiental deve ser incluído nos currículos escolares como um conteúdo a ser ministrado em diversas áreas de ensino, e não como uma área de conhecimento específico. Assim, a Educação Ambiental não deve ser considerada um tipo especial de educação, mas, de um processo contínuo e longo de aprendizagem, em que estão envolvidos família, escola, sociedade e poder público.

Essa mesma autora entende que os temas transversais podem proporcionar a união entre o saber científico escolar e o cotidiano dos alunos, desde que os educadores se proponham a trabalhar temas de interesse social em consenso com o coletivo escolar e, assim, as áreas de conhecimento passam a adquirir a qualidade de instrumentos, cujo uso e domínio levam a obtenção de resultados objetivos.

Um tema interessante e atual é a gestão dos recursos de energia renováveis, tamanha é sua importância na efetivação da sustentabilidade planetária. Não se deve esquecer que a eficiência de qualquer projeto alternativo e sustentável depende da disseminação de informações que, muitas vezes, é fornecida pela escola.

A abordagem transversal deve permitir a reabilitação da capacidade do diálogo tão necessário na prática educativa, porém difícil de ser concretizada, dada a fragmentação dos conteúdos disciplinares. 
0 ambiente escolar deve ser um espaço para se estabelecer ligações interdisciplinares e estimular atitudes conscientes dos sujeitos envolvidos, por meio de comportamentos sociais justos e ambientalmente saudáveis. É nesse ambiente que se deve desenvolver métodos efetivos para que cada indivíduo envolvido compreenda que a natureza não é fonte inesgotável de recursos naturais e que suas reservas são finitas, e que devem ser utilizadas de forma racional e consciente, evitando, dessa forma, seu mau uso e o desperdício.

Interessante imaginar um espaço de conhecimento onde se promova a conscientização para o uso responsável de fontes de energia e respeito ao meio ambiente. Daí a importância e a necessidade da utilização dos recursos naturais renováveis como uma nova forma de se pensar a vida no planeta.

Lira e Cândido (2008) afirmam que os desequilíbrios ambientais globais demonstram o erro de percepção sobre a inesgotabilidade de recursos naturais existentes na natureza. $E$, diante dessa visão errônea, deverá haver mudança de comportamento e de paradigmas no que se refere à visão econômica, social e ecológica. Daí, o importante papel da Educação Ambiental em desenvolver novos conhecimentos, valores, atitudes para a concepção do meio ambiente ecologicamente equilibrado, levando em consideração a qualidade de vida das presentes e futuras gerações.

Importante ressaltar que a Educação Ambiental é um campo do conhecimento que ainda se encontra em construção, ela se realiza aos poucos, sendo organizada numa visão histórica em que haja respeito as necessidades socioculturais de cada comunidade e de cada época.

Entende Reigota (2006, p. 87) que a "educação ambiental deve ser baseada no diálogo entre gerações e culturas, na busca da cidadania local, continental e planetária, bem como na perspectiva de uma sociedade mais justa”.
Não obstante, ensina Phillippi Junior (2004, p. 165) que "a educação é a transformação do sujeito que ao transformar-se, transforma o seu entorno". Nesse sentido, pode-se entender que a Educação Ambiental é sustentáculo na gestão dos recursos naturais, uma vez que a eficiência dessa gestão depende do grau de instrução cultural, educacional e social de uma comunidade.

\section{A METODOLOGIA APLICADA ÀS PRÁTICAS DE EDUCAÇ̃̃̃O AMBIENTAL NAS ESCOLAS BRASILEIRAS}

A Educação Ambiental pode ser transmitida por inúmeros métodos educacionais dentro do ambiente escolar. 0 mais adequado é que cada educador estabeleça o seu método e que esteja sempre em consonância com as características dos educandos.

Afirma Reigota (1994) que se pode utilizar os seguintes métodos educacionais: o chamado método passivo, aquele que somente o educador expõe seus argumentos; o método ativo, os educandos participam a partir de suas experiências relacionadas ao tema proposto; descritivo, em que os educandos aprendem definições de conceitos e descrevem suas impressões e experiências relacionadas ao tema e o método e o método analítico, aquele em que os educandos complementam e explanação do educador com dados e informações e respondem a uma série de questões sobre o tema.

Segundo esse autor, o método ativo pressupõe que o processo pedagógico seja aberto, democrático e que haja diálogo entre os próprios alunos; entre eles, os professores e a administração da escola e também com a comunidade em que vive e com a sociedade civil em geral.

Entende, dessa maneira, que a Educação Ambiental deve considerar a participação do aluno-cidadão 
na solução dos problemas ambientais. Esse aluno- cidadão deve ter a oportunidade de questionamento, propor soluções para possível resolução de problemas ambientais, tais como, utilização de fontes alternativas e renováveis de energia.

Assim, deve-se desenvolver dentro do ambiente escolar diversas atividades ambientais, onde o indivíduo deixa de ser agente passivo, tornando-se participativo dentro do processo educacional. Assim, afirma Freire (1987, p. 39) "ninguém educa ninguém, ninguém se educa a si mesmo, os homens se educam em comunhão, mediatizados pelo mundo". Para esse autor, o ambiente escolar é um lugar de transformação e como tal dispõe de meios e metodologias para colocar em prática atividades que promovam essas transformações.

Nesse sentido, o educando deve ser agente atuante e participativo, tornando-o elemento essencial do processo.

\section{CONSIDERAÇÕES FINAIS}

A relevância da Educação Ambiental na construção de uma sociedade mais sustentável é cada vez mais debatida e, por isso, vem demandando a gestão de programas e ações orientadas dentro e fora da comunidade escolar.

Atualmente, muita importância é dada a energia renovável, obtida de fontes naturais capazes de se regenerar e se renovar. Por essa razão, o incentivo em pesquisas por fontes alternativas e renováveis são indispensáveis para fomentar a diversificação do parque energético brasileiro.

Constitui um desafio para a escola e para toda a sociedade entender a importância da Educação Ambiental voltada para o uso racional e eficiente das fontes renováveis de energia do planeta.
Entretanto, mesmo com a introdução da Educação Ambiental nas instituições de ensino, nem sempre acontece a mudança de consciência e de atitudes em relação ao meio ambiente.

A escola passa a ser ferramenta para a construção de uma cidadania ecológica crítica e sensível aos problemas ambientais nos dias de hoje. Deve-se apresentar ao aluno-cidadão a ideia de que o mundo pode crescer impulsionado por fontes renováveis de energia e, com isso, diminuir consideravelmente as fontes não renováveis. Para isso é preciso um trabalho intenso e árduo de educadores, pesquisadores, comunidade envolvida, educandos, além de uma estruturação do setor em torno da conservação da energia e políticas públicas de apoio ao uso das fontes de energias renováveis.

A questão ambiental debatida e concretizada no ambiente escolar pode fomentar iniciativas que transcendam esse ambiente, atingindo o bairro, o município. Esse espaço escolar deve garantir a democratização de informações ambientais, estimulando e fortalecendo uma consciência crítica sobre a problemática ambiental dos impactos gerados pela utilização desmedida dos recursos naturais não renováveis como fonte de energia.

E mesmo quando a Educação Ambiental só é discutida dentro dos muros escolares, deve ser abordada de forma sistemática, transversal e multidisciplinar, em todos os níveis de ensino e em todas as atividades escolares.

A defesa da qualidade ambiental está umbilicalmente relacionada com o exercício da cidadania.

Diante do que foi exposto neste trabalho, faz-se necessário um ambicioso investimento no Plano de Educação Ambiental, com novas estratégias e linguagens, capazes de ampliar as possibilidades de envolvimento, sensibilização e mobilização das instituições de ensino e da própria sociedade. 
Portanto, o grande desafio da Educação Ambiental diante da problemática do uso exacerbado dos recursos naturais não renováveis como fonte de energia está em conceber e colocar em prática, iniciativas que priorizem o uso adequado dessas energias renováveis, por meio de programas interdisciplinares e transversais que sensibilizem e mobilizem o aluno-cidadão e toda a sociedade.

O desenvolvimento e a implementação de tecnologias de energias renováveis devem ser acelerados de forma ambientalmente responsável e as academias de ciência, engenharia e medicina do mundo, em parceria com as Nações Unidas e muitas outras instituições e indivíduos envolvidos, estão alinhadas para trabalhar juntos para ajudar a enfrentar esse desafio urgente.

\section{REFERÊNCIAS}

BARBOSA, Erivaldo Moreira; NÓBREGA, Maria de Fátima. $O$ Direito Ambiental em Perspectiva: da hermenêutica-sistêmica ao saber ambiental. Veredas do Direito, v.10, n.20, Julho/Dezembro de 2013.

BRASIL. Ministério da Educação. Coordenação Geral de Educação Ambiental. Ministério do Meio Ambiente. Diretoria de Educação Ambiental. Programa Nacional de Educação Ambiental - ProNEA. 3.ed. Brasília: MEC/MMA, 2005.

BRASIL. Ministério do Meio Ambiente. Catálogo de publicações do Órgão Gestor da Política Nacional de Educação Ambiental. Disponível em: <http://www. mma.gov.br/port/sdi/ea/og/pog/index.htm>. Acesso em: 20 nov. 2014.

BRASIL. Ministério do Meio Ambiente. Diretoria de Educação Ambiental. Disponível em: <http://www. mma.gov.br/educambiental. Acesso em: 20 nov. 2014.

BRASIL. Ministério da Educação. Coordenação Geral de Educação Ambiental. Disponível em: <http://www. mec.gov.br/secad>. Acesso em: 19 nov. 2014.

BRASIL. Ministério da Educação e Cultura. Parâmetros Curriculares Nacionais: meio ambiente e saúde. v.9. Brasília, 1997.

BRASIL. Ministério do Meio Ambiente. Lei $\mathbf{n}$. 9.795/1999. Dispõe sobre educação ambiental, institui a Política Nacional de Educação Ambiental e dá outras providências.

BRASIL. Ministério do Meio Ambiente. Departamento de Educação Ambiental. Vamos cuidar do Brasil: conceitos e práticas em educação ambiental na escola [Coordenação: Soraia Silva de Mello, Rachel Trajber]. - Brasília: Ministério da Educação, Coordenação Geral de Educação Ambiental: Ministério do Meio Ambiente, Departamento de Educação Ambiental: UNESCO, 2007.

CARVALHO, I. C. M. A invenção ecológica: narrativas e trajetórias da educação ambiental no Brasil. Porto Alegre: UFRGS, 2001.

CHALITA, Gabriel. Educação: a solução está no afeto. São Paulo: Gente, 2002.

CONFERÊNCIA DE TBILISI. Disponível em <http:// www.mma.gov.br/port/sdi/ea/deds/pdfs/decltbilisi. pdf>. Acesso em: 21 nov. 2014.

DIAS, G. F. Atividades interdisciplinares em EA. São Paulo: Global, 1994.

DIAS, G.F. Educação Ambiental: princípios e práticas. 3.ed. São Paulo: Gaia, 1994.

FRACALANZA, H.; AMARAL, I. A. do; GOUVEIA, M. S. F. 0 ensino de ciências no primeiro grau. Rio de Janeiro: Paz e Terra, 1983.

FREIRE, A. M. Educação para a sustentabilidade: Implicações para o Currículo Escolar e para a Formação 
de Professores. Pesquisa em Educação Ambiental, 2(1), 2007.

FREIRE, Paulo. Educação e mudança. São Paulo: Atual, 1986.

FREIRE, P. Educação: o sonho possível. In: BRANDÃO, C. O. Educador: vida e morte. Rio de Janeiro: Graal, 1986.

FREIRE, Paulo. Pedagogia do oprimido. 17.ed. Rio de Janeiro: Paz e Terra, 1987.

GOLDEMBERG, J. \& VILLANUEVA, L. D. Energia, meio ambiente \& desenvolvimento. 2.ed. rev. São Paulo: Universidade de São Paulo, 2001.

GOMES, P. C. C. Geografia e Modernidade. Rio de Janeiro: Bertrand Brasil, 1996.

GUARESCHI, P.; JOVCHELOVITCH, S. (org.). Textos em representações sociais.

Petrópolis: Vozes, 1994.

GUIMARÃES, Mauro. A dimensão ambiental na educação. Campinas: Papirus, 1995.

HARTMANN, A.; ZIMMERMANN, E. A sustentabilidade como proposta interdisciplinar para o ensino médio. IV Encontro de Pesquisa em Educação Ambiental Questões epistemológicas contemporâneas: o debate modernidade e pós-modernidade, Rio Claro. São Paulo, 2007.

HINRICHS, Roger A.; KLEINBACH, Merlin. Energia e meio ambiente. 4.ed. Trad. São Paulo: Cengage Learning, 2010.

HOGAN, D.J.; VIEIRA, P. F. (Org). Dilemas socioambientais e desenvolvimento

sustentável. Campinas: Unicamp, 1992.

HOLZER, W. A discussão fenomenológica sobre os conceitos de paisagem e lugar, território e meio am- biente. Território, Rio de Janeiro: LAGET/UERJ, v.3, jul. /dez.1997.

IBGE. Censo demográfico 2000. Disponível em: <http://www.ibge.gov.br>. Acesso em: 21 nov.2014.

JACOBI, P. R. Cidade e Meio ambiente: Percepções e prática em São Paulo. São

Paulo: Annablume, 2000.

LAYRARGUES, P. Educação no processo da gestão ambiental: criando vontades políticas, promovendo a mudança. Simpósio sul brasileiro de educação ambiental. Erechim: EdiFAPES, 2002.

LEFF, ENRIQUE. Epistemologia ambiental. São Paulo: Cortez, 2001.

LEFF, ENRIQUE. Saber Ambiental: sustentabilidade, racionalidade, complexidade, Poder. Enrique Leff. Trad. Lúcia Mathilde Endlich Orth. Petrópolis, Rio de Janeiro: Vozes, 2001.

LEITE, Ana Lúcia Tostes de Aquino Leite \& MEDINA-MININNI (Coordenadoras), Nana: Educação Ambiental: curso básico a distância: documentos e legislação da educação ambiental, 5.v., 2.ed., MMA, Brasília, 2001.

LIRA, WS; CANDIDO, G. A. Análise dos modelos de indicadores no contexto do desenvolvimento sustentável. Revista Perspectivas Contemporâneas. Campo Mourão. v.3, n.1, 2008.

NOGUEIRA, Luiz Augusto Horta; WALTER, Arnoldo. O sistema de produção de eletricidade a partir da biomassa. In: CORTEZ, Luis Augusto Barbosa; LORA, Electo E. Silva; GÓMEZ, E. O. (orgs). Biomassa para energia. Campinas: Unicamp, 2008.

PHILLIPPI JR, A. Uma introdução à questão ambiental. In: PHILIPPI, A. Jr, ROMÉRO, M. A.; BRUNA, G. C. (Orgs.) Curso de Gestão Ambiental. Barueri: Manole, 2004. 
REIGOTA, Marcos. 0 que é educação ambiental. São Paulo, Brasiliense, 2006.

REIGOTA, Marcos. Meio ambiente e representação social. São Paulo: Cortez, 1995.

REIGOTA, Marcos. 0 que é educação ambiental. São Paulo: Brasiliense, 1994.

RIOS, A. W. S. Educação em energia: fator essencial de mudança comportamental para o uso racional de energia. Revista ciências exatas, Taubaté, v.12. n.2, 2006.
SOUZA, F.F.C. Educação Ambiental em busca de vida digna. Porto Alegre: Revista Mundo Jovem, n.265, 1995.

TALOMANI Jandira L B. SAMPAIO, Aloísio Costa. Educação Ambiental da Prática Pedagógica à Cidadania. São Paulo: Escrituras, 2003.

VIEIRA, P.F.; WEBER, J. (orgs.). Introdução geral: sociedades, natureza e desenvolvimento viável. In: P. F. Vieira e J. Weber (orgs.). Gestão de recursos naturais renováveis e desenvolvimento: novos desafios para a pesquisa ambiental. São Paulo: Cortez, 2000.

1. Mestranda em Direito Ambiental e Desenvolvimento Sustentável pela Escola Superior Dom Helder Câmara. Especialista em Direito do Trabalho pela Universidade Gama Filho/RJ. Bacharel em direito pela Pontifícia Universidade Católica de Minas Gerais. Funcionária Pública. E-mail: advmaia1@ hotmail.com 